https://doi.org/10.48009/1_iis_2009_214-224

\title{
A FOLLOW-UP STUDY OF SAP CERTIFICATION GRADUATES
}

\author{
Frank J. Andera, Central Michigan University, Frank.Andera@cmich.edu
}

\begin{abstract}
The purpose of this study was to determine the impact of the SAP Academy and SAP Certification for Central Michigan University's past undergraduate and graduate participants. Data was collected through a survey which asked participants about their satisfaction with the Academy and how it has impacted their careers and professional life. While there has been research done regarding the impact of SAP courses, little research has been done on the effects of the certification Academy. Students were very satisfied with the Academy and felt that it broadened their career opportunities and better prepared them for various job tasks. Employers were impressed with the Academy, and many students felt that their participation gave them the confidence to pursue other certifications and trainings. The SAP Certification Academy was also highly recommended for future CMU students, and the majority agreed that it had a positive impact on their careers.
\end{abstract}

Keywords: SAP, SAP University Alliance, IS Curriculum, Enterprise Software, SAP Certification, Enterprise Resource Planning

\section{INTRODUCTION}

As the market continues to expand globally, and as customer interactions with businesses increase, the use of enterprise software (ES) has dramatically increased as managers and customers alike demand real-time information [17]. Along with this increased usage, the need for personnel with experience in this field has also increased [4]. Recognizing this demand, SAP AG initiated the SAP University Alliance Program (SAP UAP) in 1996 [4, 15]. In 1997, Central Michigan University (CMU) was selected to be one of the first five universities in the SAP UAP, allowing the CMU College of Business Administration (CBA) to pave the way for integrating SAP software into both the undergraduate and graduate business programs. Using a generous donation of SAP R/3 software from SAP AG, students gained an in-depth understanding of enterprise resource planning (ERP) systems through direct contact. Research shows that this hands-on approach adds to the understanding of business integration and motivates students as they enter the job market [5]. These positive effects are also in line with the original purpose of the SAP UAP, which aims to increase students' knowledge of integrated business processes while giving faculty the opportunity to use cutting-edge technology in their curriculum [9].

Enterprise resource planning ties an enterprise's functions (finance, manufacturing, logistics, etc.) into a single database and allows for the analysis of sales, production, and human resources, among others, all while keeping a complete trail of documentation. Enterprise software such as SAP R/3 incorporates the core transaction processing activities of a business, which goes beyond just resource planning [12]. By using a single $\mathrm{ES}$, managers are able to understand a holistic view of their company without using multiple software packages. In addition, this helps to eliminate problems stemming from a lack of information or information inconsistency by holding information in a singular database where multiple users can access and edit data pertaining to their departments [17]. Through the use of various modules, communication within and between departments is simplified and streamlined, allowing data to be exchanged and analyzed efficiently and effectively [6]. Another key advantage to using a system such as SAP R/3 is that it is highly customizable and can be used for small businesses, large corporations, or any business in between. Also, SAP is globally compatible with handling multiple currencies and factor in procedures and policies for international business [17].

Aside from these benefits, however, there are challenges associated with implementing and using these systems that have created great demand for employees with ES knowledge. For a large company, it can take several years and tens of millions of dollars to fully implement a successful system [17]. With that amount of money on the line, companies want to ensure that their goals will be met and that the system will be secure without a risk of system failure [17]. In addition, it is important that IT developers are aware of enterprise strategy throughout the implementation process, and that the system supports this strategy [16]. By training graduates on SAP, they become valuable assets to 
companies since they have a comprehensive understanding of ES and can use that knowledge to align company strategy, project goals, and the enterprise system itself.

From the beginning of the CMU/SAP University Alliance Program, the College of Business sought to integrate ERP into several classes for both undergraduate and graduate students. As of 2003, sixteen SAP-supported courses had been integrated into the CBA curriculum, as shown below in Table 1 [3].

Table 1: SAP R/3 Supported Courses

\begin{tabular}{|l|l|}
\hline ACC 370S & Accounting Systems and Controls \\
\hline MGT 320S & Human Resource Management \\
\hline MGT 333S & Purchasing Management \\
\hline MKT 431S & Logistics Operations \\
\hline FIN 482S & Working Capital Management \\
\hline BIS 247S & SAP R/3 Fundamentals \\
\hline BIS 357S & ABAP Programming Fundamentals \\
\hline BIS 497C & SAP Configuration \\
\hline BIS 630S & System Analysis \& Design-Accelerated SAP \\
\hline MBA 619S & Accounting Information for Managers \\
\hline MGT 597S & ERP: Business Process Integration Supported by SAP R/3 \\
\hline MGT 633S & Human Resource Management \\
\hline BIS 647S & SAP Enterprise Software Management \\
\hline MBA 797S & Enterprise Resource Planning: Integrated Business Processes \\
\hline BIS 657S & ABAP Programming for Managerial Systems \\
\hline BIS 697C & SAP R/3 Configuration and Implementation \\
\hline
\end{tabular}

On both the undergraduate and graduate level, classes have been offered for a variety of students in different programs [7]. SAP R/3 is utilized in these classes through a business simulation which allows users to complete real-world transactions and see the impact of these on the rest of the organization. At CMU, an SAP component course is one that incorporates the SAP R/3 System in about $20 \%$ of the course content [7]. Through this experience students are able to gain a more comprehensive view of the business as a whole [5]. To date, nearly 4,000 students, with every CBA major represented, have participated in SAP-supported courses. In a 2003 study by Hayen and Andera, students responded that they were generally satisfied with the SAP component courses offered at CMU. $72 \%$ of respondents believed that the courses would be helpful in fulfilling their career objectives, and $82 \%$ believed that participating in these courses would enhance their employment opportunities [7]. With the great success achieved through incorporating SAP R/3 into the College of Business curriculum, CMU sought out other opportunities to enhance students' exposure to SAP.
In addition to these SAP R/3 component courses, upon reevaluation of the Central Michigan University B.S.B.A. degree, the College of Business Administration decided it was time to integrate SAP $\mathrm{R} / 3$ into the curriculum for every graduate of the program. A special course was created, BUS 301Integrated Business Experience, which created cohort teams of students that worked together on a business simulation which stressed the importance of business process integration. This course was created to help increase ERP system knowledge and to ultimately prepare graduates for an actual business setting. By taking BUS 301 alongside three other "integrated core" classes, students have been able to learn about various business processes and then immediately understand their function in a business simulation. According to exit surveys taken by students during the first year of the integrated core, it is evident that the students were able to gain a much deeper understanding of the business as a whole, and how SAP or other ERP software works within a company [11].

In 2000, a new opportunity presented itself for students in CMU's College of Business Administration. SAP AG offered students a two- 
week SAP Process Integration Certification Academy or "boot camp" designed to accomplish three goals: (1) To provide an overview of process-oriented management, for a business point of view; (2) To gain knowledge of core business processes; (3) To integrate acquired $\mathrm{R} / 3$ System skills through the knowledge of basic business processes [14]. Central Michigan University has continued to offer the SAP Certification Academy annually since 2000 and, for the first time in North America as part of the SAP UAP, CMU was able to offer two concurrent academies in 2008 with 58 participants, bringing the total number of academy participants at CMU to 202. The certification academy is taught by faculty from SAP AG and students attend ten days of class, culminating in the SAP certification exam. Listed in Table 2 are the concepts covered throughout the SAP Certification Academy:

Table 2: Academy Concepts

\begin{tabular}{|l|l|}
\hline ERP Basics & Lifecycle Data Management \\
\hline ERP SAP NetWeaver & Program and Project Management \\
\hline Business Warehouse & Enterprise Asset Management \\
\hline Sales Order Management & Human Capital Management \\
\hline Material Planning & Financial Accounting \\
\hline Manufacturing Execution & Management Accounting \\
\hline Procurement Cycle & Strategic Enterprise Management \\
\hline Inventory and Warehouse Management & \\
\hline
\end{tabular}

graduates will also benefit from a higher starting

In 2000, five universities were chosen to host the first trial-run SAP academies. California State University - Chico, University of South Dakota, and Central Michigan University were chosen to host undergraduate academies, while two universities, Louisiana State University and UCLA, were chosen to host graduate SAP academies. This pilot program was designed to gauge the effectiveness of the SAP certification program in a college setting [9]. After the first academy was completed, CMU distributed surveys to academy participants regarding their impressions of the academy and its' potential impact on their current and future career prospects. The overwhelming majority of students agreed that the academy would help them in their careers and that the academy helped them to gain a more in-depth understanding of integrated business processes [9].

A study by Andera in 2004 shows that graduates at Central Michigan University that have taken at least one SAP-supported course have earned higher starting salaries than those students without an SAP course. For some majors, the difference in starting salaries was as great as $\$ 10,000$ [1]. With such a difference in starting salaries for students with SAPsupported classes, it is hypothesized that Academy salary.

While these surveys provided insight into the immediate effects of participation in the SAP Certification Academy, it is important to consider the value of the SAP Certification Academy for alumni and how the academy has or has not helped them in their careers. The purpose of this study was to determine the value of the SAP Academy and SAP Certification to CMU's past undergraduate and graduate students in their initial employment and in their careers.

\section{METHODOLOGY}

Through the use of the CMU SAP University Alliance Program database, past academy participants were identified and contacted through mailing addresses provided by the CMU alumni house. While 126 students participated in the CMU SAP Certification Academies in the years 2000 through 2006, only 116 were able to be contacted due to various circumstances. Of the students contacted, 48 responses were collected and used in the study analysis. 
The survey consisted of twenty-seven items, twentyfour of which were multiple choice, and three of which were open-ended. With the exception of questions 6-8 and 19-24, all of the multiple choice questions used a seven-point scale ranging from (1) "extremely dissatisfied" or "strongly disagree" to (7) "extremely satisfied" or "strongly agree," and (4) representing "don't know/no opinion." Listed in Table 3 are the items included in the survey aside from demographic questions and two items related to starting and current salary:

\section{Table 3: Non-demographic survey questions}

\section{Item Question}

1 The academy was useful in helping to fulfill my career objectives.

2 Which of the following describes your overall level of satisfaction with SAP academy experience?

3 Which of the following describes your overall level of satisfaction with the content of the Academy in learning the concepts and issues involved in integrated business processes? Which of the following describes your overall level of satisfaction with time and effort commitment required to participate in the Academy?

5 Participating in the Academy enhanced employment opportunities.

$6 \quad$ Have you worked for an employer that uses SAP?

7 If so, how many years have you been working for an employer that uses SAP?

8 Are you currently working with SAP?

9 My current and/or past employer was impressed by my participation in the SAP Academy.

10 Participating in the SAP Academy was important to my current and/or past employer(s).

11 I consider my participation in the SAP Academy to be important in obtaining my position with my current employer and/or future employer.

12 Participation in the Academy increased my earnings since graduation.

13 Participation in the Academy had an impact on my career and current/past employment.

14 My understanding of the relevant issues about the SAP R/3 System and integrated business processes were improved by participation in the SAP Academy.

15 The confidence I gained from the SAP Academy has helped me to pursue other certifications.

16 Participation in the SAP Academy has helped in my SAP-related job assignments.

17 Participation in the SAP Academy has helped in my non-SAP-related job assignments.

18 Would you recommend the SAP Academy to future SAP students at CMU?

The final three survey items were open-ended questions asking participants to explain the most important benefits of the Academy, how the Academy experience has helped them to pursue other professional opportunities, and any other comments they had regarding the academy. The survey was designed to gain insight into the ways the SAP Certification Academy helped graduates in their careers as well as their personal and professional development as well as students' general opinions regarding their satisfaction with the academy. 
Figure 1: Mean response

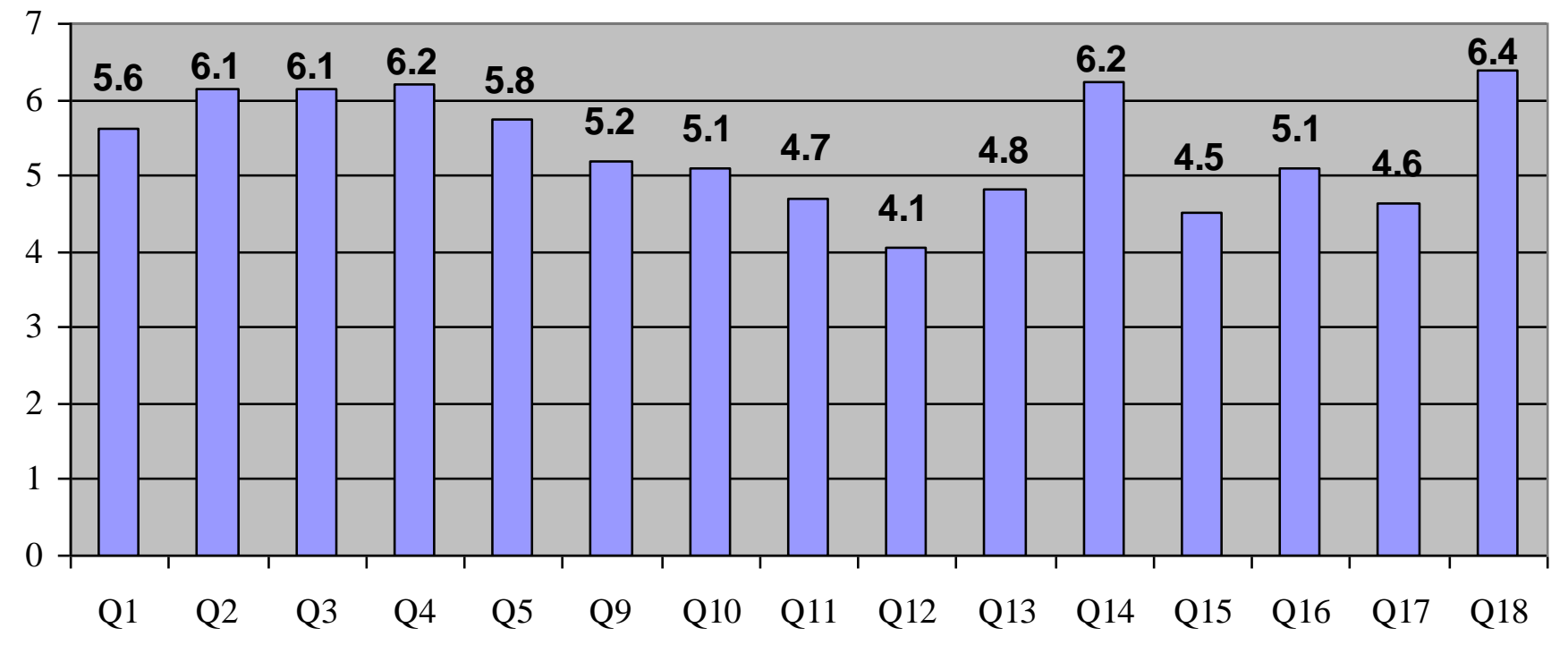

\section{FINDINGS}

As evidenced by Figure 1, academy participants generally had a positive reaction to their academy experience. Question 12 had the lowest mean response at 4.1 with $20.8 \%$ of respondents choosing "don't know / no opinion" for their answer. $41.7 \%$ of respondents agreed that academy participation increased their earnings since graduation, and 37.5\% disagreed. While this contradicts the research by Andera in 2004 [1], information from these graduates may not be completely accurate. The subjective nature of the survey items, changes in career direction, or a lack of knowledge of the job market could account for this lower mean, as many students may not be fully aware of the impact of the SAP Academy on their salaries.

The item with the highest mean response was Question 18, whether the students would recommend the Academy to future SAP students at CMU. With a mean of $6.4,93.8 \%$ of respondents agreed that they would recommend the academy, with $62.5 \%$ answering "strongly agree." Other survey items can provide insight into the strengths of the SAP Academy to help better understand why these students feel the Academy would be valuable to future students.
Question 2 asks respondents about their overall level of satisfaction with the Academy experience as a whole. $95.8 \%$ agreed that they were at least "slightly satisfied" with the Academy, and 39.6\% responded that they were "extremely satisfied." These are very positive results, especially considering that no participants were "extremely dissatisfied" or "moderately dissatisfied." Only one survey respondent was "slightly dissatisfied," and in his or her qualitative comments remarked that he or she "...could have learned about this in any class at CMU." For this question, it appears that the clear majority of students were satisfied with their experience in the SAP Academy as a whole.

The next aspect of the SAP Academy that is important to consider is students' satisfaction with the Academy's content (item 3). This question also yielded extremely positive results, with $95.8 \%$ of respondents agreeing that they were satisfied with the Academy's content in learning the concepts and issues involved in integrated business processes. Along with this, participants were asked about whether the Academy improved their understanding of the SAP R/3 System and integrated business processes. An overwhelming 95.8\% of students agreed with this statement, with 50\% stating that they "strongly agree." In the free-response portion of the survey, students were asked what they felt were the most important benefits of the Academy, and the majority stated that they benefited most from 
understanding the entire business process from the SAP perspective. One student explained, "It gives you a really good idea of the integration of the different modules of ERP and how one process affects the other modules in an organization." Another participant said "The most important benefit of the Academy was an understanding of all the modules in SAP. In order to understand one particular module, one must know how each module builds off of and affects the other modules." According to the respondents' answers, it is evident that students are satisfied with the content of the Academy and believe that it has helped increase their knowledge of the SAP R/3 system and integrated business processes as a whole.

Another factor that may influence students' overall satisfaction with the Academy is their satisfaction with regard to the amount of time and effort necessary to participate in the Academy (item 4). For this item, $91.7 \%$ of students agreed that they were satisfied, with $4.2 \%$ of respondents "slightly dissatisfied" and 4.2\% selecting "don't know/no opinion." One student remarked in their comments that "The SAP Academy was difficult (long hours), but it was all worth it as it helped in understanding the course fully and accomplishing what I have during this short duration of time." Another respondent discussed a recent promotion they received and remarked that "I honestly feel that this accomplishment was possible based on my willingness to work long hours, be flexible and be available whenever necessary-things I improved while I was in the Academy." Yet another student discussed that "[The Academy] teaches you to perform under pressure in strict timelines with a lot at stake." While the SAP Academy does require long hours and intense study preparation, it appears that students find that this level of time and effort is reasonable and beneficial. 
Aside from understanding Academy participants' feelings on the Academy itself, the purpose of this study was also to see how this experience has or has not influenced participants' careers. When participants were asked if the Academy was useful in
Administration), and MCS (Master of Computer Science). Together, participants with MIS or MSIS degrees account for $76.9 \%$ of employees that have worked with SAP in their career. Results such as these suggest that the SAP Academy is best directed

\section{Figure 2: Majors/Degrees of participants that have used SAP in the workplace}
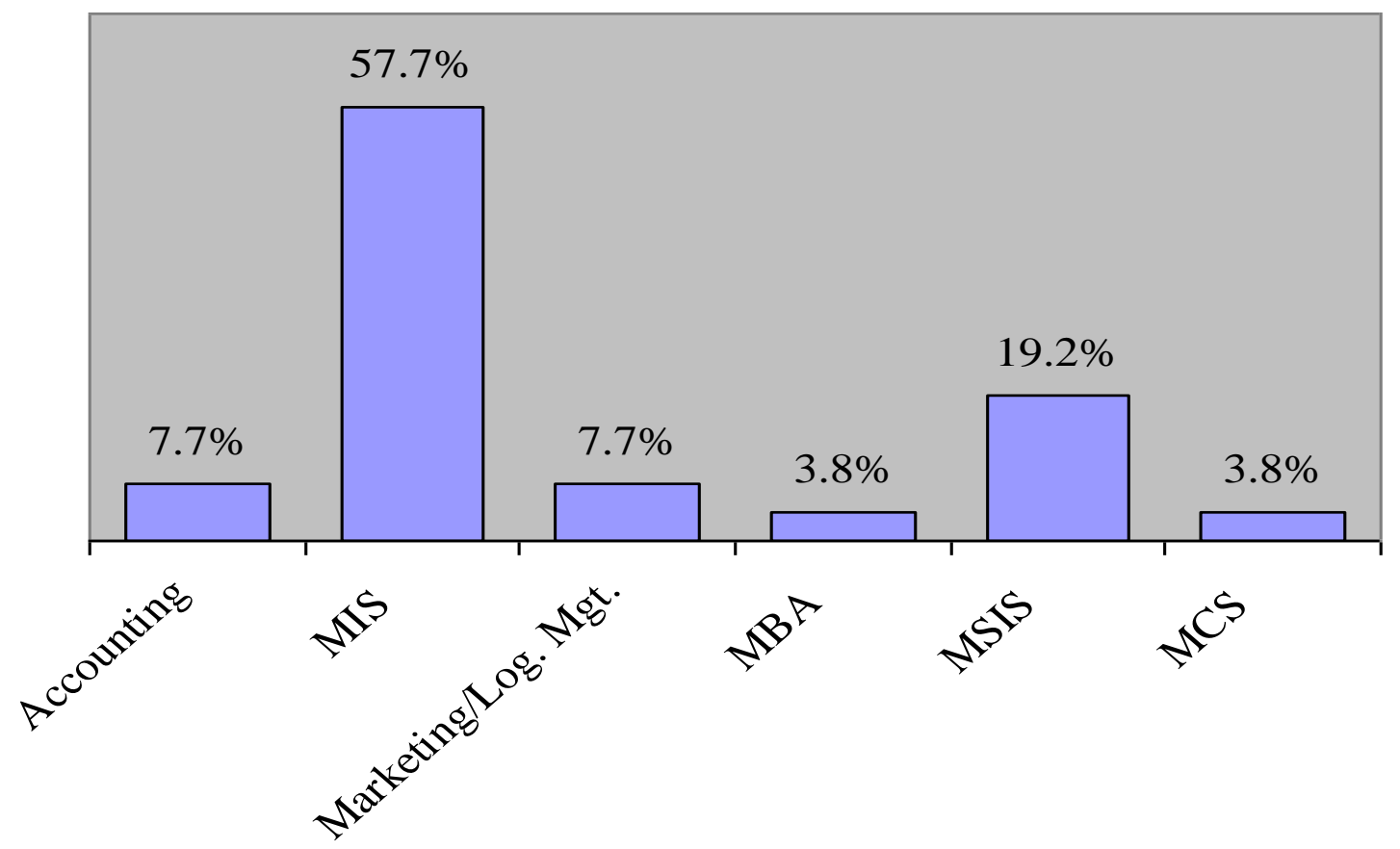

fulfilling their career objectives (item 1), $81.2 \%$ of those surveyed agreed. Since the mean was not significantly different for any field of study, it can be concluded that the SAP Academy is appropriate for any major within the College of Business. To add to this, $64.6 \%$ of survey respondents have, at some time, worked for an employer that uses SAP, while 54.2\% of respondents currently work with SAP. Of the Management Information Systems (MIS) majors, $81.8 \%$ have worked for a company that uses SAP and $63.6 \%$ work with SAP in their current jobs. Figure 2 displays the majors of all of the respondents that have worked for an employer that uses SAP. As shown, MIS and MSIS (Master of Science in Information Systems) were the most common majors of participants using SAP. Other fields of study were also represented: accounting, marketing/logistics management, MBA (Master of Business

Students were also asked to rate how important their participation in the SAP Academy was to their towards MIS and MSIS students, although there are SAP opportunities for students in different fields of study. Regardless of whether an employee obtains an SAP-related job, the SAP Academy may have an effect on his or her career. $56.3 \%$ of those surveyed agreed that their current and/or past employers were impressed by their participation in the SAP Academy (item 9), and only $10.4 \%$ felt that their employers were unimpressed by their participation. Out of the MIS and MSIS students, $66.6 \%$ felt that their employers were impressed and only $7.4 \%$ felt that their employer was unimpressed. Many respondents commented that the SAP Academy looked very strong on their résumés, such as the following response: "[The Academy] opens up many new job opportunities. Employers search for you and it's great to use this in an interview."

current and/or past employer(s) (item 10). $60.4 \%$ of students agreed with this statement while $6.3 \%$ 
moderately disagreed and $14.6 \%$ slightly disagreed. Many students stated that they use the Academy as a conversation starter during job interviews. One respondent said "The Academy made me stand out from other applicants and is always a talking point during interviews or conversations related to possible positions." Another stated that "The academy sounds flashy to employers," enforcing the fact that the majority of students agree that the Academy is an impressive item for potential employers to notice.

Another question asked about if the Academy had an impact on participants' past or current employment (item 13). As shown in Figure 3, the responses were fairly spread out; however $58.3 \%$ of respondents
MIS/MSIS students, $74.1 \%$ agreed that the Academy helped them to obtain their job. Many believed that the Academy allowed them to move up quickly within their company. One student explained "I achieved a well-paying job and also am more confident in my knowledge of SAP. This transfers over to how successful I've been at my job." Another wrote "I'm one of the top SAP consultants in my region, and the SAP Academy put me head-andshoulders above many of my peers almost immediately." Furthermore, $81.3 \%$ of those surveyed agreed that the SAP Academy enhanced their employment opportunities (item 5). Many students recognized this in their free-responses, and as one explained, “Although I haven't had the chance to use

\section{Figure 3: Participation in the Academy had an impact on my career and current/past employment.}

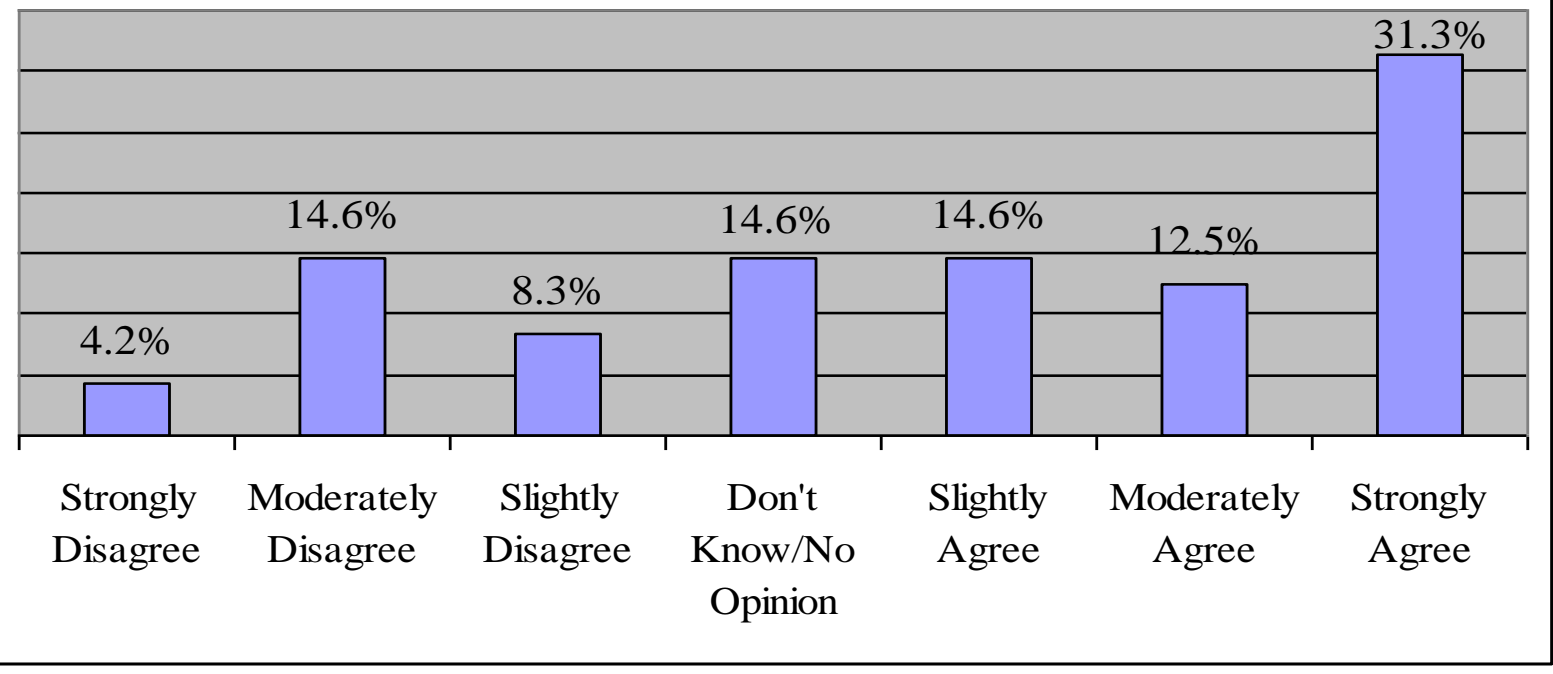

agreed that the Academy had an impact on their career and current/past employment. Many participants mentioned that the Academy allowed them to broaden their job search and find better job opportunities, such as the following student who said "After the Academy, my job options increased. It was easier to find a job and my starting salary increased." Several participants also described that their improved understanding of integrated business processes also allowed them to perform better on the job, with a comprehensive understanding of the business as a whole.

On the same lines, participants were asked if they felt that the SAP Academy was important in obtaining their position with their current and/or future employer(s) (item 11). Once again, the majority of participants, $58.3 \%$, agreed that this was true. Of the
SAP in my career, participating in the SAP Academy helped to broaden my search when looking for new job opportunities." It is apparent that the SAP Academy has value for job-seekers and employers in the job market.

Given that employers recognize the utility of the SAP Academy in the market, it is also important to consider whether or not the skills learned in the Academy are useful in the workplace. Respondents were asked whether or not the SAP Academy has helped them in both their SAP-related job assignments and non-SAP-related job assignments. Of the participants that have worked with SAP at some point in their career, $89.2 \%$ agreed that their Academy participation helped them in their SAPrelated job assignments (item 16). $39.3 \%$ of those working with SAP strongly agreed with this 
statement, showing that the concepts taught in the Academy are applicable in the workplace. According to the survey responses, Academy participants were able to gain other things from this experience, as $62.5 \%$ reported that participation in the SAP Academy has helped in their non-SAP-related job assignments (item 17). Since $35.4 \%$ of respondents only selected "slightly agree," it can be inferred that skills learned in the Academy can be indirectly applied to other situations, such as problem-solving skills or a better understanding of integrated business processes. Some students addressed this issue in the qualitative portion of the study. As one participant explained, "The Academy helped in challenging me to obtain more technical certifications. The intense two-week class improved my study habits." These participants' opinions reflect the idea that the Academy is beneficial even for students that do not ultimately end up working with SAP.

Participants in the SAP Academy also benefit from increased confidence after taking part in the Academy. Students were asked to what extent they agreed that "The confidence I gained from the SAP Academy has helped me to pursue other certifications" (item 15). Of the 34 responses to this item, $61.8 \%$ agreed with the statement. This agreement was expanded upon in the free-response portion of the survey where many students commented that after completing the Academy they felt more confident and able to complete other certifications. One participant describes his or her experience as follows:

"As an intern at Deloitte and Touche LLP in 2001 with 40 others, I was the only person from CMU. There were 20 students from MSU [Michigan State University] and 15 from the University of Michigan. However, the SAP Academy and certification helped instill confidence in me in this environment. Also, the certification instilled confidence in me to pursue three other certifications: Certified Information Systems Auditor, Certified Internal Auditor, and Certified Fraud Examiner."

Other students also listed the professional certifications they received after completing the Academy. Some of these certifications include: Project Management Professional, Oracle PL/SQL Developer, Certified Public Accountant, CPIM, ISA Certification, Certified Medical Representative, Six Sigma Certification, as well as a number of certification programs offered within individual companies. Through the confidence gained from the SAP Academy, past participants have been able to

Volume X, No. 1, 2009 further their educations and become even more marketable to prospective employers.

While these quantitative questions provide a wellrounded view of students' opinions, their qualitative responses provide even more insight into the impact of the SAP Academy. Students graduating with SAP Certification have been able to enter all areas of the market and put their skills to use in a variety of ways. One student shared that "Because of the Academy, I had the chance to live in Germany for a year developing a global common template of SAP to be rolled out globally." Other students have also had the opportunity to travel abroad as a result of the Academy, "The SAP certification and experience that I gained at CMU has allowed me to travel to Sao Paulo, Brazil and Melbourne, Australia for work. I wouldn't have had these opportunities without my SAP training from CMU." Another Academy graduate described his or her new job working with SAP workflow and procurement for Defense Supply Center, which warehouses items related to the various U.S. military branches. A number of students also had experience in SAP implementation at a number of large corporations.

It appears that the Academy is doing well and has provided students with great opportunities, survey respondents also provided advice for how the Academy could be improved for future students. Several students suggested that upon completion of the Academy, help should be provided to help participants incorporate the Academy into their job search by showing examples of SAP-related jobs or by providing advice on how to discuss the Academy on a résumé. Another student suggested that SAP AG and the SAP UAP should continue to expand in order to connect students across the globe with more opportunities. While this participant agreed that there were many opportunities available for employees trained in SAP, he or she was unaware of how to pursue these careers. Furthermore, some students felt that the presentation of material in the SAP Academy was not conducive to their learning styles, and that some other method of delivery should be tried for future Academies.

Multiple respondents left recommendations for students currently involved in the SAP program; as one respondent noted, "I highly recommend taking the Academy. I feel it is as close to real world SAP experience as many will have while still in school." Another student said "SAP is huge right now and it is growing. CMU's leadership experiences and an SAP background should help students land an excellent job." Based on comments such as these and the aforementioned survey results, it is evident that many 
students have benefited from the SAP Academy both on the job and in the job market. Students have been generally satisfied with all aspects of the Academy, and most would recommend it to other students wishing to have a competitive advantage.

\section{CONCLUSIONS AND FUTURE RESEARCH}

The results of this survey show that, overall, the SAP Certification Academy has been received well by students. Most students agreed that they were able to improve their understanding of the SAP R/3 System and integrated business processes through this Academy. Although the Academy was difficult and rigorous, most participants also felt that it was worth the time and effort expended during the two-week course. After completion of the Academy, over half of the students worked in a job that used SAP, while over three-quarters of the Management Information Systems majors worked in an SAP-related position, and the large majority of these students reported that the Academy was helpful in their SAP-related job duties, and over half of the students also agreed that the SAP Academy helped even with jobs not pertaining to SAP.

The Academy also opened up career opportunities for participants, and employers were impressed by this certification. It gave students an opportunity to speak about the challenges of the Academy and gave several a sense of confidence that led them to pursue other certifications. The doors of opportunity were also opened for many Academy participants-several described how the SAP Academy affected their careers, from travel opportunities to early promotions. Although the results were generally positive, there is still room for improvement in the SAP Academy. Several students expressed interest in learning more about incorporating their SAP Certification into their job searches and interviews. Other students also mentioned that the certification Academy provides too broad of a perspective of the SAP R/3 system, and that potential employers were more interested in job seekers with a more specialized skill set. To alleviate this problem, Academy participants should be encouraged to enroll in not only the SAP Academy, but a variety of the SAP-supported courses offered through Central Michigan University.

In the future, it may be beneficial to study the impacts of the entire SAP curriculum offered through CMU, including both the Academy and the various courses involving SAP. Rather than isolating the courses and the Academy as in the past, researchers should analyze how the two are connected, and the benefits of the interaction between specific classes and the Academy. Furthermore, it

Volume X, No. 1, 2009 may be interesting to review past Academy participants from their employers' perspectives in order to understand how the concepts of the SAP Certification Academy have carried through to the work place. If Academy students are satisfied with the experience of the SAP Academy, it is also important that their employers are satisfied with the skills gained through the Academy, and that their SAP-Certified employees are applying their newly acquired knowledge of SAP R/3 and integrated business processes.

\section{REFERENCES}

[1] Andera, F. J. "Salary Comparison Study of Central Michigan University's College of Business Administration Graduates who Have and Have Not Taken SAP R/3 Supported Classes." Issues in Information Systems, 5:1, 2004, pp. 8-14.

[2] Antonucci, Y. L., G. Corbit, G. Stewart, and A. L. Harris. "Enterprise Systems Education: Where are We/ Where Are We Going?" Journal of Information Systems Education, 15:3, 2004, pp. 227-234.

[3] "Courses and Certificates." College of Business Administration SAP University Alliance Program, 2006. http://sapua.cba.cmich.edu/default2.asp?33\%2 E3. (May, 2008)

[4] Corbit, G. and J. Mensching. "Integrating SAP $\mathrm{R} / 3$ into a College of Business Curriculum: Lessons Learned," Information Technology and Management, 1:4, 2000, pp. 247-258.

[5] Draijer, C. and D. J. Schenk. "Best Practices of Business Simulation with SAP R/3," Journal of Information Systems Education, 15:3, 2004, pp. 261-265.

[6] Hayen, Roger. SAP R/3 Enterprise Software: An Introduction. McGraw-Hill / Irwin, New York, NY, 2007.

[7] Hayen, R. L. and F. J. Andera. "Assessment of Student Satisfaction with SAP R/3 Component Courses," Issues in Information Systems. 4:1, 2003, pp. 150-156.

[8] Hayen, R.L. and F. J. Andera. "Analysis of Enterprise Software Deployment in Academic Curricula," Issues in Information Systems. 7:1, 2006, pp. 273-283.

Issues in Information Systems 
[9] Hayen, R.L. and J. J. Cappel. "Certification in Enterprise Software: An SAP R/3 University Alliance Program Experiment," Issues in Information Systems, 2:1, 2001, pp. 132-138.

[10] Hayen, R.L., M.C. Holmes, and J.J. Cappel. "A Framework for SAP R/3 Enterprise Software Instruction," Journal of Computer Information Systems. 40:2, 1999, pp. 79-85.

[11] Hayen, R.L., D.E. Vetter, and Z. Huang. "Using ERP in Curriculum Integration: A Case Study," Issues in Information Systems. 8:1, 2007, pp. 204-210.

[12] Laudon, K. C. and J. P. Laudon. Management Information Systems, $8^{\text {th }}$ ed., Prentice-Hall, Upper Saddle River, NJ, 2004.

[13] MacKinnon, R. "Integration of ERP in the Business Curriculum," Issues in Information Systems. 3:1, 2002, pp. 413-419.

[14] "SAP Academy Certification." College of Business Administration SAP University Alliance Program, 2006. http://sapua.cba.cmich.edu/default2.asp?33\%2 E5 (May, 2008)

[15] SAP AG. "What's New with the SAP Educational Alliance Program in the U.S." SAP America, Inc., Philadelphia, PA, September 2001.

[16] Soja, P. "Examining the Conditions of ERP Implementations: Lessons Learnt from Adopters," Business Process Management Journal. 14:1, 2008, pp. 105-123.

[17] Stair, R. and G. Reynolds. Principles of Information Systems: A Managerial Approach, $8^{\text {th }}$ ed., Thomson Course Technology, Boston, MA, 2008, pp. 343-374. 